\title{
Social judgment and attitudes: warmer, more social, and less conscious
}

\author{
NORBERT SCHWARZ* \\ University of Michigan, USA
}

\begin{abstract}
Developments in social judgment research during the last two decades have broadened the explanatory power of the information processing perspective by paying attention to the social context of human judgment, the importance of 'warm' cognition, and the role of nonconscious processes. The application of social cognition theorizing to the formation of attitude judgments provided new insights into classic issues of attitude research, suggesting that attitudes may be fruitfully conceptualized as temporary constructions. Implications of these developments, open issues, and potentially fruitful avenues for future research are discussed. Copyright (C) 2000 John Wiley \& Sons, Ltd.
\end{abstract}

The editors charged the contributors to this millennium series with a daunting task: 'Assess where we are as a field and where we might venture in the new century (and do so on no more than 40 manuscript pages).' Needless to say, any assessment of where we are is likely to be controversial and predictions about the future of a creative field are bound to be wrong. This being said, this article provides an opinionated review of selected developments in judgment and attitude research and identifies open issues that may provide fruitful avenues for future research. Using the information processing paradigm as a backdrop, I first discuss three general developments, namely the rediscovery of the 'social' in social judgment, the renewed interest in 'warm' cognition, and the current fascination with nonconscious processes. Subsequently, I turn to the implications for attitude research and question the usefulness of the traditional attitude concept in favor of a mental construal approach.

\section{SOCIAL JUDGMENT AND INFORMATION PROCESSING}

Following two decades of research dominated by variations of the cognitive consistency theme, the introduction of the information processing paradigm in the 1970's

*Correspondence to: Dr Norbert Schwarz, ISR, University of Michigan, Ann Arbor, MI 48106-1248 USA. e-mail: nschwarz@umich.edu 
had a liberating influence on social judgment research (for an introduction to the paradigm see Lachman, Lachman \& Butterfield, 1979). Drawing on general models of information encoding, storage and retrieval, social psychologists began to address a broad range of issues within a unified conceptual framework (for reviews see Devine, Hamilton \& Ostrom, 1994; Martin \& Clark, 1990; Strack, 1988). On the theoretical side, the traditional organization of the field by substantive topics gave way to an increasing emphasis on basic processes that cut across diverse phenomena, as impressively reflected in Social Psychology: Handbook of Basic Principles (Higgins \& Kruglanski, 1996). On the methodological side, the new paradigm's emphasis on detailed process models changed social psychologists' standards for what counts as appropriate evidence. As Taylor (1998, p. 48) noted, 'it was no longer enough to detail a theoretical model and use the results as confirmation of the model. If one stated what one thought the process was, one had to demonstrate the intervening steps.'

As philosophers and historians of science are aware, however, the metaphors that guide a given paradigm focus attention on some questions at the expense of others, even if these 'other' questions could, in principle, be fruitfully conceptualized within the paradigm (see Kuhn, 1962; Root-Bernstein, 1989; Weimer \& Palermo, 1973). In the present case, the computer metaphor underlying the information processing paradigm stimulated extensive research into the encoding, storage, and retrieval of information that proved extremely fruitful for social judgment research. Other aspects of human judgment, however, were less likely to come into focus, although they are amenable to an information processing analysis.

First, the paradigm's focus on encoding, storage and retrieval processes fostered a concentration on individuals as isolated information processors. This focus resulted in a neglect of the social context in which humans do much of their thinking, both in terms of the immediate interactional context and in terms of individuals' embeddedness in a broader cultural context. As a result, 'social psychology found itself transformed into a field now mainly concerned not with human social action, but with human beings as thinkers and information processors about social stimuli' (Forgas, 1981, p. 3; see also Fiske, 1992; Schneider, 1991). But even the study of 'human beings as thinkers and information processors' suffered from this neglect, as subsequent research into situated cognition, conversational aspects of social judgment, and cultural variations in basic judgmental processes demonstrated.

Second, reflecting its historical roots (see Lachman et al., 1979), the paradigm, as adopted from cognitive psychology, did not invite attention to subjective experiences and emotional and motivational influences, thus facilitating an emphasis on 'cold' cognition and deliberate inferences at the expense of research into 'warm' cognition and nonconscious processes (for critical discussions see Banaji, Lemm \& Carpenter, in press; Kunda, 1999; Sorrentino \& Higgins, 1986; Zajonc, 1980). In the process, the complex treatment of perceivers' goals and needs that characterized the New Look (e.g. Bruner, 1957), for example, was reduced to simpler processing goals, like forming an accurate impression versus remembering the material presented in the experiment (e.g. Hamilton, Katz \& Leirer, 1980; for a critical discussion see Hilton \& Darley, 1991). As Taylor (1998, p. 72) observed, 'Although social psychologists were unwilling to adopt a radial behaviorist view of the person, the willingness to live with a fundamentally cognitive view of the social being, to the relative exclusion of motivational, affective, and behavioral processes took root, at least temporarily' (emphasis added). 
As social cognition research unfolded, however, all these topics became major foci of social psychology (and if the reviews of this paper are any indication, some social cognition researchers may feel that these topics have never been neglected to begin with). Thus, researchers rediscovered that humans do much of their thinking in a social context and turned to the exploration of socially situated cognition and the interplay of cognition and communication in human reasoning. Complementing this interest in the immediate social context, cultural influences on social judgment are about to become a 'hot' topic. Similarly, the role of moods, emotions, goals and motivations in human reasoning received considerable attention and the field is currently experiencing a surge of interest in nonconscious processes. The picture that emerges from these lines of work is consistent with social psychology's latest metaphor, that portrays the information processor as a motivated tactician.

This metaphor builds on William James' (1890, p. 333) pragmatic credo that 'my thinking is first and last and always for the sake of my doing'. It emphasizes that humans have 'multiple information processing strategies available, selecting among them on the basis of goals, motives, needs, and forces in the environment' (Taylor, 1998 , p. 50). In fact, even nonconscious, automatic processes are often tuned to facilitate goal attainment, although the motivated tactician's ability to flexibly adjust cognitive processes to situational requirements is not without limits. Note that this metaphor does not question the truism that humans are information processors. It merely highlights that information stands in the service of, and is tuned to meet, the individual's goals and needs in a given context. Attention to this pragmatic, socially contextualized, and 'warm' nature of human cognition has greatly extended the explanatory power of the information processing approach beyond the constraints of the models we initially adopted from cognitive psychology (see Lachman et al., 1979; Neisser, 1967). In my reading, this extension of the range of questions asked, rather than the straightforward application of established principles of cognitive psychology to 'social' rather than 'nonsocial' objects as targets of judgment, is the key contribution of social cognition research to psychological theorizing. Next, I turn to selected aspects of these developments.

\section{REDISCOVERING THE 'SOCIAL' IN SOCIAL JUDGMENT}

If thinking is for doing, we may expect that individuals adjust their cognitive strategies to the immediate social context. Indeed, a growing body of work demonstrates such adjustments in response to variables like the accountability of actors (e.g. Tetlock, 1992), their anticipation of audience reactions (e.g. McCann \& Higgins, 1992), and their interdependence and position in a power hierarchy (e.g. Fiske \& Depret, 1996). Unfortunately, a comprehensive review of research into situated cognition is beyond the scope of this article (see Levine, Resnick \& Higgins, 1993; Resnick, Levine \& Teasly, 1991). Instead, I first focus on the social situation that is most relevant to social judgment research: the research setting in which we test our theories. Subsequently, I turn to another implication of the notion that thinking is for doing, namely that cognitive strategies should also be tuned to meet the requirements of the actor's broader cultural context. Both bodies of research highlight the potential costs of investigating basic cognitive processes within a very limited social and cultural context. 


\section{Situated Cognition in the Lab: The Case of Judgmental Biases}

One of the core intellectual contributions of social judgment research is the identification of a wide range of judgmental biases and shortcomings. No matter what we think about, we often get it wrong: we rely on nondiagnostic individuating information at the expense of more diagnostic baserate information, ignore situational influences in explaining social behavior, are unduly influenced by surface characteristics of the tasks presented to us, are easily misled by suggestive questions, and so on and on (for reviews see Griffin, Gonzalez \& Varey, in press; Nisbett \& Ross, 1980; Kahneman, Slovic \& Tversky, 1982). After a quarter century of research into judgmental biases, the good news is: things aren't (quite) that bad. On the one hand, the biases identified in this research tradition are robust and reliably replicable. Moreover, the assumed underlying processes have been confirmed in numerous studies. On the other hand, however, the errors we make in the laboratory are much less likely to result in mistakes in daily life than the research findings would seem to suggest. Instead, the field's treatment of humans as isolated information processors has resulted in a profound overestimation of the fallibility of human judgment, providing an involuntary illustration of the power of situated cognition.

At the heart of this discrepancy is a basic misunderstanding about the nature of communication in a research setting. According to the tacit assumptions that underlie the conduct of conversation in daily life, 'communicated information comes with a guarantee of relevance' (Sperber \& Wilson, 1986, p. vi) and listeners are entitled to assume that the speaker tries to be informative, truthful, relevant, and clear. Moreover, listeners interpret the speakers' utterances 'on the assumption that they are trying to live up to these ideals' (Clark \& Clark, 1977, p. 122). Bringing these assumptions to the research situation, participants assume that every contribution of the researcher is informative, truthful and clear - and certainly relevant to the aims of the ongoing conversation (or why else would it be presented?). Unfortunately, they miss one crucial point. Whereas the researcher is likely to observe conversational maxims in daily life, he or she is much less likely to do so in the research setting. In fact, the researcher may provide information that is neither relevant, nor truthful, informative and clear-and may have carefully designed the situation to suggest otherwise. Having no reason to suspect uncooperative behavior, however, participants are likely to find meaning the researcher's contributions, rendering logically irrelevant information conversationally relevant.

Supporting this analysis, a growing body of research demonstrates that many of the apparent biases and shortcomings of human judgment are attenuated or eliminated when this basic misunderstanding is taken care of (for reviews to Bless, Strack \& Schwarz, 1993; Hilton, 1995; Hilton \& Slugoski, in press; Schwarz, 1994, 1996). When participants are aware that the usual 'guarantee of relevance' does not hold, they prefer baserate information over nondiagnostic individuating information (e.g. Schwarz, Strack, Hilton \& Naderer, 1991b; Krosnick, Li \& Lehman, 1990); are less likely to show the fundamental attribution error (e.g. Wright \& Wells, 1988); and are less likely to be influenced by misleading questions in eyewitness testimony (e.g. Dodd \& Bradshaw, 1980). In fact, when explicitly asked, participants usually seem aware that the normatively irrelevant information is of little informational value (e.g. Miller, Schmidt, Meyer \& Colella, 1984). Nevertheless, they typically proceed to use it because the sheer fact that it has been presented renders it conversationally relevant in 
the given context. Moreover, increasing individuals' motivation to arrive at a defensible judgment does not attenuate reliance on normatively irrelevant information presented by the researcher. To the contrary, it increases their efforts to find meaning in the material presented to them (e.g. Tetlock \& Boettger, 1996).

As a consequence, the procedures typically used in psychological research are likely to result in an overestimation of the size and the pervasiveness of judgmental biases. Note, however, that this analysis does not imply that violations of conversational norms are the sole source of judgmental biases. Like most robust phenomena, judgmental biases are likely to have many determinants. If we are to understand their operation in natural contexts, however, we need to ensure that their emergence in laboratory experiments does not reflect the operation of determinants that are unlikely to hold in other settings (see Schwarz, 1996). How exactly we can accomplish this, however, is a tricky and largely unresolved issue that has been insufficiently addressed in this line of work.

We now know that we can (a) reliably exaggerate many biases by violating conversational norms; can (b) reliably attenuate them by undermining the assumption that the experimenter is a cooperative communicator; or can (c) often avoid their emergence by being cooperative communicators who do not present misleading information in the first place. But where do we go from here? How can we study, for example, how individuals select, weight, and use information of differential diagnosticity when every piece of information we present is rendered relevant by the sheer fact that we present it, thus biasing the very processes we want to explore? One potentially promising answer is that we need to heed the socially situated nature of cognition, paying closer attention to the conditions under which people encounter the tasks of interest in daily life (for a related discussion see Wyer \& Gruenfeld, 1995). As an example, consider a study on leading questions in eyewitness testimony reported by Dodd and Bradshaw (1980). Like numerous other researchers, Dodd and Bradshaw observed that leading questions biased eyewitness memory, yet they only obtained this effect when the misleading question was asked by the experimenter, not when it was asked by the defendant's lawyer. Presumably, their participants assumed that the experimenter was a cooperative communicator, whereas their real world knowledge about the adversarial nature of courtroom proceedings entailed that the defendant's lawyer may very well not be cooperative. Hence, they drew on the information implied by the misleading question in the former but not in the latter case, in contrast to the assumption that misleading question effects are due to context independent distortions of memory (e.g. Loftus, 1979). Findings of this type illustrate how real world knowledge about the social context affects cognitive performance and suggest that we may miss the boat by limiting our investigations to a social setting that renders much of this real world knowledge inapplicable: the psychological laboratory.

In fact, the sheer knowledge that one participates in a psychological study may itself affect participants' judgments. For example, Norenzayan and Schwarz (1999) presented a newspaper account of a mass murder case on the letterhead of an 'Institute for Personality Research' or an 'Institute for Social Research' and asked participants for causal explanations. As expected, participants provided more dispositional and fewer social explanations when the letterhead identified the researcher as a personality psychologist rather than a social scientist, resulting in a stronger fundamental attribution error under 'psychological' conditions. This presumably reflects that participants, as cooperative communicators, inferred the 
researcher's likely epistemic interests from the affiliation indicated in the letterhead and did their best to provide answers that are informative in light of these interests.

Throughout, research into the interplay of cognitive and conversational processes and the nature of socially situated cognition highlights the need to study social judgment across a broader range of social settings. Complementing a pragmatic analysis of judgmental biases, Wyer and Gruenfeld (1995) addressed pragmatic aspects of person perception, noting that 'much of our theoretical and empirical knowledge about social information processing has been obtained under laboratory conditions that only faintly resemble the social situations in which information is usually acquired in everyday life' (p.49). Their discussion converges with the above concerns: How can we study which information people search for, and attend to, when the sheer fact that we present it may distort the very processes we are interested in? Resolving this issue without giving up the power of controlled experimentation is one of the key methodological challenges for social judgment research.

\section{Cultural Differences in Judgment and Reasoning}

Complementing attention to the impact of the immediate social context, social judgment researchers also began to address cultural influences on reasoning processes (for reviews see Fiske, Kitamaya, Markus \& Nisbett, 1998; Miller, in press; Nisbett, Peng, Choi \& Norenzayan, in press). Their findings challenge the description of 'the mind as a machine or computer that is the same in all times and places, while only the raw materials processed by the machinery or the data in the computer vary' (Fiske et al., 1998, p.918). To date, experimental research has mostly focused on comparisons of Western and East Asian cultures and has documented two profound and related differences in reasoning style.

In the social domain, Western cultures conceptualize the self as autonomous and relatively independent, characterized by unique 'internal' attributes that are largely independent of the momentary social situation. In contrast, East Asian cultures conceptualize the self as mutually interdependent and constituted in relationship with others (Markus \& Kitayama, 1991). Given these tacit metatheories, Westerners explain social behavior in terms of individual characteristics, whereas East Asians draw on the social field of which the behavior is a part, resulting in reliable differences in causal attribution, impression formation, and prediction (e.g. Cousins, 1989; Markus \& Kitayama, 1991; Miller, 1984; Morris \& Peng, 1994). The differential emphasis on the social field is further reflected in the structure of autobiographical memory (e.g. Han, Leichtman \& Wang, 1998) and individuals' knowledge about their own and others' behavior (e.g. Ji, Schwarz \& Nisbett, in press). Moreover, different metatheories of self foster different self-protective biases in judgment and prediction (e.g. Heine \& Lehman, 1999).

Similarly, Western reasoning about the physical world is characterized by an analytical epistemological orientation that privileges deductive logic and the decomposition of a phenomenon into component parts. In contrast, the dominant East Asian epistemological orientation is more holistic and emphasizes the relationship between parts, rather than their component functions. Moreover, Westerners value formal logic with its emphasis on mutually exclusive truth values (which, historically, is a Western invention), whereas the Eastern dialectic tradition allows that both A and 
not-A can be true, as illustrated by the Chinese proverb that the opposite of a great truth is also a great truth. These differences reflect the intellectual traditions of the respective cultures (see Lloyd, 1990; Nakamura, 1985) and influence performance across a variety of reasoning tasks (for reviews see Nisbett, Peng, Choi \& Norenzayan, in press; Miller, in press; Peng \& Nisbett, 1999). For example, East Asians have been found to outperform Westerners in covariation detection (e.g. Peng \& Nisbett, 1997), consistent with the higher emphasis on the interrelatedness of elements. However, they perform less successfully on category learning tasks that require the application of formal rules and pay more attention to family resemblance (e.g. Norenzayan, 1999). Because holistic reasoners draw on a wider range of factors in the field in arriving at a causal explanation, they are less likely to experience surprise and show more pronounced hindsight biases (e.g. Choi, Nisbett \& Norenzayan, 1999).

The accumulating findings pertaining to social as well as nonsocial reasoning tasks increasingly challenge the assumption that cultural variations in cognition solely reflect the application of the same basic processes to different, culture-specific content. Of course, universals can be formulated (e.g. 'Individuals use the applicable procedure that is most accessible'). But it becomes increasingly obvious that such universals remain uninformative unless we can specify which procedures are most accessible and considered applicable in a given cultural and situational context. Unfortunately, we are often unable to do so and many assumed universals (from attribution to self-enhancement) run risk of 'being spurious, in that they describe processes which, in fact, are culturally-specific' (Miller, in press). The extent to which this is the case is an empirical issue, but that the concern holds for some of social psychology's core generalizations is by now well established.

\section{Conclusions}

In combination, the findings addressed in the preceding sections reiterate what is usually considered social psychology's signature contribution to psychological theorizing: human cognition and behavior are context dependent. Ironically, we tend to ignore this insight in the conduct of our research and limit our investigations to a narrow range of social and cultural contexts. To what extent the current interest is situated cognition and cultural differences will actually change this state of affairs remains to be seen. If thinking is for doing, however, we need to pay more attention to the contextualized nature of human cognition, heeding the core message of our field. The pragmatic perspective that is at the heart of the motivated tactician metaphor further suggests that we need to evaluate performance against a criterion of 'what works', in contrast to an exclusive focus on normative models. As the philosopher Stich (1990, p. 24) noted, 'there are no intrinsic epistemic virtues. (...) Cognitive mechanisms or processes are to be viewed as tools or policies and evaluated in much the same way that we evaluate other tools or policies'.

\section{'WARM' COGNITION: AFFECT AND MOTIVATION}

Social psychologists traditionally assumed that motivational and affective processes play a key role in social judgment and are at the heart of most judgmental biases. In 
sharp contrast, research under the influence of the information processing paradigm initially traced judgmental biases to 'cold' cognitive processes and questioned the role of affect and motivation as explanatory constructs. Analyzing the literature that purportedly demonstrated motivated reasoning, several seminal reviews concluded that all relevant findings could be explained in purely cognitive terms, without invoking motivation (e.g. Miller \& Ross, 1975; Nisbett \& Ross, 1980). As a result, 'a battle developed regarding which of the two, motivation or cognition, was a better explanation of the phenomenon' (Sorrentino and Higgins, 1986, p. 7). This battle remained largely inconclusive (see Ross \& Fletcher, 1985; Tetlock \& Levi, 1982) and gave way to a synergistic view that suggests that 'motivation and cognition are, in fact, inseparable' (Sorrentino \& Higgins, 1986, p. 8). As the examples below illustrate, a growing body of research indicates that affect and motivation exert their influence on social judgment through the recruitment of 'cold' processes, rendering a juxtaposition of 'hot' versus 'cold' processes increasingly untenable.

\section{Motivated Reasoning}

Dating back to Heider's seminal volume on The Psychology of Interpersonal Relations (1958), numerous attribution studies documented pervasive self-serving biases (for a review see Miller \& Ross, 1975). In fact, Heider himself suggested that causal attributions have to meet two criteria to be acceptable to the attributer: '(1) The reason has to fit the wishes of the person and (2) the datum has to be plausibly derived from the reason' (1958, p.172; emphasis added). While the motivation-versuscognition debate juxtaposed these two criteria, the field has recently come full circle.

It is now well documented, and widely accepted, that individuals' desires can exert a profound influence on their judgments, consistent with Heider's (1958) first postulate. Yet, this influence is constrained by the individual's ability to muster supportive evidence, consistent with Heider's second postulate (see Dunning, in press; Kunda, 1990, 1999, for extensive reviews). In mustering supportive evidence, individuals draw on the 'cold' processes that have been identified as the cognitive basis of judgmental biases by researchers who attempted to refute motivational accounts - but which specific 'cold' process they draw on is a function of their 'hot' goals. Thus, the 'cold' mechanisms of confirmatory hypothesis testing (e.g. Klayman \& Ha, 1987) may be recruited in the service of desired conclusions (e.g. Sanitioso, Kunda \& Fong, 1990), different criteria and inference rules may be selected to arrive at desired outcomes (e.g. Doosje, Spears \& Koomen, 1995), complex causal theories may be constructed to bolster preferred inferences (e.g. Dunning, Leuenberger \& Sherman, 1995), or key concepts may be defined in self-serving terms (e.g. Dunning \& Cohen, 1992). If these 'cold' cognitive mechanisms do not provide sufficiently compelling support for our desired conclusions, however, we grudgingly abandon what we would have liked to believe (Kunda, 1990). Hence, cold processes serve as well as constrain our ability to reach 'hot' goals.

Note that the evolving synergistic view of motivated reasoning is nicely compatible with the pragmatic emphasis of the motivated tactician metaphor (see the contributions in Gollwitzer \& Bargh, 1996). Gollwitzer and his colleagues, for example, demonstrated that the use of motivated reasoning strategies depends on the individual's position in the action sequence. While contemplating what to do, individuals 
are likely to adopt an accuracy goal and consider a wide range of relevant information in a careful and balanced manner. Once a decision is made, however, their thought processes are focused on achieving the desired outcome and reflect the mechanisms of motivated reasoning discussed above (for reviews see Gollwitzer \& Moskowitz, 1996; Oettingen \& Gollwitzer, in press).

In sum, the field has moved beyond the juxtaposition of 'hot' versus 'cold' processes and motivation has been assigned a central role in cognitive theories (e.g. Kruglanski, 1996; Kunda, 1999). The present trend to conceptualize the role of motivation, affect and cognition in the context of self-regulation processes will further bolster this synergistic view (see Carver, in press; Higgins, 1997; Kruglanski, 1996; and the contributions in Martin \& Tesser, 1996).

\section{Moods and Emotions}

In a similar vein, the traditional juxtaposition of reason and emotion has been replaced by detailed analyses of the intricate interplay of feeling and thinking. On the one hand, cognitive appraisals are a crucial determinant of the emotions we experience (for a review see Clore, Schwarz \& Conway, 1995); on the other hand, our emotions can profoundly influence our reasoning processes (for reviews see Bless, in press; Forgas, 1995; Schwarz \& Clore, 1996; Wyer, Clore \& Isbell, 1999).

Following pioneering work by Alice Isen and colleagues in the 1970s (see Isen, 1984, for a review), numerous studies documented that almost any target is evaluated more positively when individuals are in a happy rather than sad mood. This phenomenon has been traced to two different processes, namely mood congruent recall of valenced information from memory (Isen, Shalker, Clark \& Carp, 1978; Bower, 1981) and the use of one's feelings as a source of information according to a 'How-do-I-feel-about-it?' heuristic (Schwarz \& Clore, 1983). While each of these process assumptions has received considerable support, the conditions under which each one is likely to hold have remained somewhat elusive. There is some consensus that mood congruent recall effects are most likely to be observed under conditions that foster systematic, elaborative judgment strategies (see Forgas, 1995), whereas reliance on one's feelings as a source of information is more likely under conditions that foster heuristic processing (see Schwarz \& Clore, 1996). Yet, many studies lack the misattribution conditions or recall measures that are necessary to diagnose the underlying process, rendering them thoroughly nondiagnostic.

Consistent with the pragmatic focus of the motivated tactician metaphor, moods have also been found to influence individuals' spontaneous choice of processing strategies, linking affect and motivation with the self-regulation of cognitive activity. While the findings bearing on formal reasoning tasks (such as syllogistic reasoning, puzzles, or anagrams) are complex and inconsistent (see Clore et al., 1994), the findings bearing on social reasoning tasks show a coherent pattern. In general, individuals in a sad mood are more likely to use a systematic, data-driven strategy of information processing, with considerable attention to detail. In contrast, individuals in a happy mood are more likely to rely on pre-existing general knowledge structures, using a top-down, heuristic strategy of information processing, with less attention to detail. These differences have been observed across a wide range of tasks, including person perception (e.g. Sinclair, 1988), stereotyping (e.g. Bodenhausen, Kramer \& 
Süsser, 1994), the use of scripts (e.g. Bless et al., 1996), and the processing of persuasive messages (e.g. Schwarz, Bless \& Bohner, 1991a).

From a pragmatic perspective, these effects can be traced to the informative functions of feelings (Schwarz, 1990; Bless \& Schwarz, 1999; for other perspectives see Fielder, 1988; Kuhl, 1983). We usually feel bad when we encounter a threat of negative or a lack of positive outcomes, and feel good when we obtain positive outcomes and are not threatened by negative ones. Hence, being in a negative mood signals a problematic situation, whereas being in a positive mood signals a benign situation. Consistent with the motivated tactician metaphor, individuals' cognitive strategies are tuned to meet the requirements signalled by their feelings, resulting in a preference for bottom-up, systematic processing when the situation is characterized as problematic, but reliance on top-down, heuristic strategies when the situation is characterized as 'business-as-usual'. Importantly, these mood effects on processing style are eliminated when the informational value of the mood is undermined (Sinclair, Mark \& Clore, 1994), paralleling findings in the evaluative judgment domain (Schwarz \& Clore, 1983). Not surprisingly, however, happy individuals' spontaneous processing style can be overridden by other goals (e.g. Wegener, Petty \& Smith, 1995) or explicit task instructions (e.g. Bless, Bohner, Schwarz \& Strack, 1990; Martin, Ward, Achee \& Wyer, 1993). What characterizes information processing under positive moods is not a general cognitive or motivational impairment, but a tendency to spontaneously rely on simplifying heuristics and general knowledge structures in the absence of goals that require otherwise, again consistent with the metaphor of the motivated tactician. The impact of negative moods, on the other hand, is difficult to override, presumably because ignoring a potential problem signal would be highly maladaptive (see Schwarz \& Clore, 1996, for a discussion).

Consistent with this informational functions perspective, neuropsychological work demonstrated that impairments in the experience of emotional reactions may dramatically impair decision making (for a review see Damasio, 1994). For example, Bechera, Damasio, Tramel, and Damasio (1997) observed that healthy individuals displayed negative affective reactions to disadvantageous moves in an experimental game. Drawing on these reactions, they began to avoid these moves long before they could consciously identify them as disadvantageous, consistent with Zajonc's (1980) controversial proposition that 'preferences need no inferences'. In contrast, patients with damage to the prefrontal cortex, which controls emotional reactions, failed to show affective learning. Lacking the danger signal provided by a negative affective response, they continued to make disadvantageous moves even after they had conscious insight into their disadvantageous nature. Findings of this type highlight the role of affective reactions in guiding behavior and illustrate that affective reactions may precede cognitive insight (LeDoux, 1996; LeDoux \& Armory, 1999; Zajonc, 1980).

Despite the progress made, work into the interplay of affect and cognition suffers from a number of important limitations. First, as Bodenhausen (1993) noted, the induced feeling is often incidental to the task. For example, participants are put in a happy or sad mood and presented with a person description that allows for individuated or category-based processing (e.g. Bodenhausen et al., 1994; Bless, Schwarz \& Kemmelmeier, 1996b). Under these conditions, participants are less likely to engage in stereotyping when they are in a sad rather than happy mood, in contrast to traditional theorizing that suggests that stereotyping would increase under negative 
affect (e.g. Allport, 1954). Yet, theories of prejudice refer to affect towards the target, not affect that is induced by other circumstances. While incidental affect may be misread as a response to the target, future research would benefit from a systematic comparison of incidental and integral affect. Unfortunately, such comparisons require some equation of the induced incidental and integral affect, while controlling for the presented information - a task that is difficult enough to discourage most researchers who pondered it.

Second, work in this area has almost exclusively focused on global moods and has largely neglected the role of specific emotions. Theoretically, the experience of a specific emotion (e.g. anger or anxiety) informs the person that the appraisal conditions underlying this emotion have been met. This information is considerably more specific than the information provided by global positive or negative moods and should elicit more specific changes in cognitive strategies (see Lerner \& Keltner, in press; Schwarz, 1990). Raghunathan and Pham (1999), for example, observed differential influences of sadness and anxiety that reflect the underlying appraisal patterns. In general, sadness is a response to the loss or absence of a reward, whereas anxiety is a response to outcome uncertainty (e.g. Ortony, Clore \& Collins, 1988). Hence, sadness can be expected to prompt a goal of reward acquisition, whereas anxiety should prompt a goal of uncertainty reduction. To test these assumptions, Raghunathan and Pham (1999) provided participants with a choice task that required a tradeoff between risk and rewards. As expected, they observed that sad individuals preferred high-risk/high-reward options, whereas anxious individuals preferred lowrisk/low-reward options. The research reviewed above, as well as Higgins' (1997) work into prevention and promotion motives, suggests that such affect-induced goals are also likely to be accompanied by different processing strategies, a possibility that provides a rich agenda for future research.

Finally, the feelings-as-information framework that guided much of this work requires the conscious experience of affect as a key ingredient (in contrast to network models, which, however, are silent with regard to affective influences on processing style). Challenging this assumption, a growing body of research in affective neuroscience suggests that some affective reactions may not be consciously experienced, but may nevertheless influence judgment, raising new questions about the mediating mechanisms ( for discussions see Winkielman, Berntson \& Cacioppo, in press; Winkielman, Zajonc \& Schwarz, 1997). On the other hand, the observation that mood effects on processing style are eliminated when the informational value of the mood is called into question (Sinclair et al., 1994) challenges neuropsychological models that attempt to trace these effects to differences in brain dopamine levels (Ashby, Isen \& Turken, 1999), a main-effect mechanism that provides little room for the emergence of inferencebased discounting effects. Disentangling the interplay of biological and cognitive processes will provide a challenging avenue for future interdisciplinary research.

\section{Conclusions}

As this selective review indicates, social judgment researchers have made considerable progress in understanding the interplay of 'cold' and 'warm' processes, an interplay that is sufficiently intricate to render a juxtaposition untenable: Cold processes can serve as well as constrain the pursuit of hot goals; feelings have informational value 
and are used in forming evaluative judgments like 'cold' pieces of information; and reasoning strategies are tuned to meet the situational requirements signalled by affective states. Further blurring the distinctions, bodily feelings (e.g. Stepper \& Strack, 1993; Strack, Martin \& Stepper, 1988) and cognitive experiences, like the ease or difficulty of recall (for a review see Schwarz, 1998) or the fluency of perception (e.g. Jacoby \& Kelley, 1987; Reber, Winkielman \& Schwarz, 1998), are used in judgment formation in much the same way as affective experiences. The emerging synergistic view of affect, motivation and cognition has enriched our understanding of social judgment and the integration of the core processes in general models of self-regulation provides a promising avenue for future research.

\section{LESS CONSCIOUS}

Although the 'unconscious' figures prominently in lay persons' understanding of what psychology is all about, research on nonconscious influences on human cognition, emotion, and behavior has long been hampered by serious methodological shortcomings and experimentally oriented psychologists viewed the study of nonconscious processes with considerable suspicion. Based on advances in experimental methodology (see Bassili, in press), this state of affairs has changed dramatically over the last decade and the investigation of processes that occur outside of the individual's conscious awareness has become one of the most exciting areas of experimental research, blurring the boundaries between cognitive, social, personality, clinical, and neuropsychology (for recent reviews see Banaji et al., in press; Bargh, 1997; Bargh \& Chartrand, 1999; Kirsch \& Lynn, 1999; Winkielman et al., in press). Avoiding the traditional connotations of the 'unconscious', this work usually refers to 'nonconscious' or 'implicit' processes. Several insights from this fast-growing body of research are of key importance to social judgment theorizing.

\section{What We Learned}

First, a growing body of research indicates that 'at least some objects in the environment, and perhaps most, are classified as good or bad within split seconds after being noticed' (Giner-Sorolla, Garcia \& Bargh, 1999, p. 93). These automatic evaluations occur effortlessly, without intention and conscious awareness, and are not limited to stimuli towards which individuals hold previously formed highly accessible attitudes (see Wegner \& Bargh, 1998, for a review). Preconscious evaluations are accompanied by an increased readiness to engage in approach or avoidance responses (Chen \& Bargh, 1999) and feed into individuals' consciously experienced mood (Bargh \& Chartrand, 1999). The emerging picture suggests that preconscious evaluative processing is highly adaptive, "creating behavioral readiness within fractions of a second to approach positive and avoid negative objects, and, through its effects on mood, serving as a signalling system for the overall safety versus danger of one's current environment. All of these effects tend to keep us in touch with the realities of our worlds in a way that bypasses the limitations of conscious self-regulation capabilities' (Bargh \& Chartrand, 1999, p. 476). 
Second, unidentified traces of past experience can influence judgment and behavior; their conscious identification, however, typically attenuates or eliminates their impact (for a review see Greenwald \& Banaji, 1995). A classic example from the social judgment domain is the mere exposure effect, i.e. the observation that repeated exposure to a stimulus increases liking (Zajonc, 1968). This effect is most reliably obtained when participants can not recognize the stimulus as having been previously presented (e.g. Kunst-Wilson \& Zajonc, 1980), and is attenuated or eliminated when participants are aware of the previous exposure (e.g. Bornstein \& D'Agostino, 1992). Its emergence presumably reflects that previous exposure increases the fluency with which the stimulus can be processed later on (Jacoby, Kelley \& Dywan, 1989), and other variables that increase perceptual fluency have been shown to produce the same effect with one single exposure (Reber et al., 1998). Similarly, the typically obtained assimilative effects of semantic priming (e.g. Higgins, Rholes \& Jones, 1976) are eliminated or reversed when individuals become aware of the potential impact of the priming episode (e.g. Martin, Seta \& Crelia, 1990; Strack, Schwarz, Bless, Kübler \& Wänke, 1993; for a review see Martin, Strack \& Stapel, in press), much as the influence of affective residuals of previous experiences is eliminated when their source is identified (Schwarz \& Clore, 1996).

Third, a growing number of experiments demonstrates automatic influences on overt behavior. For example, priming the elderly stereotype induced participants to walk more slowly (Bargh, Chen \& Burrows, 1996), whereas priming the professor stereotype increased, and priming the soccer hooligan stereotype decreased, individuals' performance on knowledge tests (Dijksterhuis \& van Knippenberg, 1998). The authors attribute these findings to a direct perception-behavior link that presumably reflects strong associative connections between the representations involved in perceiving and acting (for reviews see Bargh, 1997; Bargh \& Chartrand, 1999).

Fourth, like any other mental representation, goals can be automatically activated by features of the environment, initiating processes of goal pursuit that parallel deliberate goal enactment (see Bargh \& Gollwitzer, 1994). These automatic processes can be intentionally employed to facilitate goal attainment: By forming an implementation intention that links critical situations with goal-directed responses, individuals may delegate the initiation of goal directed behavior to anticipated situational cues (for a review see Gollwitzer, 1999). This strategic use of automatic processes has been found to reliably facilitate goal directed behavior (Gollwitzer, 1999), although the automatic activation of goals may also result in undesired consequences (Bargh, Raymond, Pryor \& Strack, 1995).

The bulk of the accumulating findings suggests that nonconscious processes serve the motivated tactician well and typically facilitate adaptive responses to the environment (Bargh \& Chartrand, 1999). On the downside, however, automatically activated knowledge structures may be inconsistent with the individual's consciously held beliefs. For example, most individuals are likely to share the stereotypic knowledge structures prevalent in their society, even when they do not endorse them (e.g. Devine, 1989). Hence, the automatic activation of these knowledge structures may result in responses that run counter to what the individual might want to do under more deliberate conditions (for a discussion see Banaji et al., in press).

Unfortunately, attempts to control unwanted effects of automatic knowledge activation may often backfire. Although we can suppress unwanted thoughts for a limited period of time, we are only successful at doing so when no other task taxes our 
cognitive resources (Wegner, 1992). When we are distracted by another task, or terminate our efforts when no longer required, the unwanted thoughts bounce back with renewed vigor, as Macrae, Bodenhausen, Milne, and Jetten (1994) demonstrated for the case of stereotype suppression (for comprehensive reviews see Wegner \& Wenzlaff, 1996, and the contributions in Wegner \& Pennebaker, 1993).

Finally, many researchers hope that implicit measures of cognition may provide an unbiased window on people's 'true' attitudes, an issue that I address below.

\section{Conclusions}

This latest wave of social judgment research has made a compelling case for the pervasive relevance of nonconscious processes and has brought the unconscious back to the center stage of psychological theorizing. At the same time, it is striking that many studies lack the independent process evidence that distinguished social cognition research from earlier experimental traditions in social psychology: How exactly we get from the manipulation to the effect often remains unclear. In fact, we often don't even know what the relevant process evidence might be. Without more detailed attention to the underlying process assumptions, however, it will remain difficult to specify how nonconscious processes interface with conscious ones. In my reading, this interface presents the most challenging conceptual task for the next few years of social judgment research.

\section{THE CONSTRUCTION OF ATTITUDES}

Most graduate programs in social psychology offer a course on 'Attitudes and Social Judgment', thus acknowledging the close relationship between both literatures while maintaining a clear distinction. Over three decades of social cognition research, this distinction has become increasingly blurred and a growing number of researchers question its usefulness. Traditionally, attitudes have been conceptualized as 'an enduring organization of motivational, emotional, perceptual, and cognitive processes with respect to some aspect of the individual's world' (Krech \& Crutchfield, 1948, p. 152). In subsequent decades, however, the attitude concept has been largely reduced to its evaluative component and many of the functions ascribed to attitudes have been reassigned to other cognitive structures. In the succinct words of Daryl Bem, 'Attitudes are likes and dislikes' (1970, p. 14).

In recent years, the study of these 'likes and dislikes' has seen two somewhat contradictory developments. One the one hand, many researchers concluded that all we assess in attitude measurement are evaluative judgments that individuals construct on the spot, based on whatever information is accessible at that time (for a review see Schwarz \& Bohner, in press). Consistent with this 'attitudes-as-judgments' perspective, the general developments discussed above apply to attitude research, from the interplay of cognitive and communicative processes (e.g. Schwarz, Strack \& Mai, 1991c) to the influence of affective states (e.g. Schwarz \& Clore, 1983) and the role of implicit processes (e.g. Greenwald \& Banaji, 1995). Conversely, conceptualizations that were initially developed in the context of attitude research can be fruitfully 
applied to human judgment in general, as highlighted in Chaiken and Trope's (1999) recent volume on Dual-Process Models in Social Psychology. On the other hand, social judgment researchers have developed implicit measures of attitudes in the hope that these measures will provide an unbiased window on people's 'true' feelings (for reviews see Bassili, in press; Banaji et al., in press). If successful, these measures would bypass the context dependency of explicit attitude reports that gave rise to the development of attitude construal models, thus reestablishing the usefulness of the traditional attitude concept. I address both issues in turn.

\section{Implicit Measures: An Unbiased Window on 'True' Attitudes?}

As noted in the discussion of nonconscious processes, most stimuli are quickly categorized as good or bad, resulting in reliable facilitation and inhibition effects on lexical decision or pronunciation tasks. While some researchers interpreted these effects as evidence for the influence of highly accessible previously formed attitudes, others concluded that they reflect a preconscious on-line evaluation process (for different perspectives see Dovidio \& Fazio, 1992; Fazio, 1995; Giner-Sorolla et al., 1999; Wegner \& Bargh, 1998). Empirically, implicit measures are only weakly related to explicit self-reports and overt behavior (e.g. Hilton \& Karpinski, 2000; for reviews see Blair, in press; Wittenbrink, Judd \& Park, 1999). What we are to conclude from this weak relationship, however, is controversial: On the one hand, it may indicate that implicit measures live up to their promise and provide a window on attitudes that respondents do not want to admit or may not even be aware of. On the other hand, it may suggest that the observed facilitation and inhibition effects merely reflect the structure of general semantic knowledge with limited implications for conscious judgment and behavior (see Schwarz \& Bohner, in press, for a more extensive discussion).

Moreover, recent findings suggest that implicit measures may be just as likely to be subject to context effects as explicit measures - an observation that is less than surprising in light of the history of social judgment research, yet threatens the hope that implicit measures may provide an unbiased window on people's 'true' feelings. For example, Glaser and Banaji (1999) observed that evaluatively extreme primes may inhibit rather than facilitate the identification of evaluatively congruent words, thus reversing the usually obtained pattern. While the processes underlying implicit context effects are not yet understood, their investigation promises to advance our understanding of nonconscious processes, much as investigations of context effects on explicit measures have advanced our understanding of evaluative judgment.

In my reading, it is unlikely that implicit measures will finally deliver the direct access to individuals' attitudes that the bogus pipeline (e.g. Sigall \& Page, 1971) failed to provide. Instead, it seems more promising to address how preconscious, automatic evaluations may feed into the processes that underlie individuals' explicit judgments and behavioral decisions. What has rendered attitude research of central importance to many social science disciplines is an interest in how people form opinions about complex social issues and a need to understand how these opinions may, or may not, relate to behavior. While the automatic classification of stimuli as good or bad is interesting in its own right, it falls short of addressing the issues that have traditionally motivated attitude research. To bring implicit phenomena to bear on these issues, we 
need a better understanding of the interface of implicit and explicit processes, which is arguably the most challenging conceptual issue of current social judgment research.

\section{Attitudes as Temporary Construals}

Whereas the work on implicit measures attempts to identify individuals' 'true' attitudes, other researchers suggested that the classic issues of attitude research may be better conceptualized in the context of general judgment models, essentially discarding the traditional attitude concept in the process (see Schwarz \& Bohner, in press). At present, the usefulness of a judgment approach is undisputed in accounting for context effects in attitude measurement and considerable progress has been made in understanding the underlying dynamics (for reviews see Schwarz, 1999; Schwarz \& Bless, 1992; Sudman, Bradburn \& Schwarz, 1996; Strack \& Martin, 1987; Tourangeau, 1999; Wilson \& Hodges, 1992). Many attitude theorists assume, however, that the observation of attitude stability over time and the emergence of strong attitudebehavior relationships challenges the portrayal of attitudes as temporary constructions. The next two sections address this concern and illustrate how construal models (e.g. Lord \& Lepper, in press; Schwarz \& Bless, 1992; Wilson \& Hodges, 1992) can provide a coherent framework for the conceptualization of these presumably challenging phenomena. Similar considerations apply to the construction of preferences in decision making (see Fischhoff, 1991; Payne, Bettman \& Johnson, 1992, 1993), yet space does not allow me to elaborate on the parallels.

For the sake of the argument, I base this discussion on an extreme assumption: People can never recall previously formed judgments and always have to start from scratch, based on information accessible at the time. As anyone who recalls that a movie was boring, but can't recall any details, will realize, this assumption is unrealistic. Nevertheless, construal models can handle the key phenomena even under these extreme conditions, as a selective discussion may illustrate (for a more fully developed argument see Schwarz \& Bohner, in press).

\section{Attitude Stability}

From the perspective of the traditional 'file-drawer' model of attitudes (Wilson \& Hodges, 1992), similar attitude reports at different points in time suggest that respondents have a 'crystallized' attitude towards the object that they can 'look up' in memory and report with some accuracy. From this perspective, instability in the reports suggests that we are assessing 'non-attitudes' (e.g. Converse, 1964), that is, opinions toward objects for which a proper attitude cannot be found in the file drawer. This assumption is circular in the absence of independent evidence for the crystallization of attitudes. More important, the widely shared hypothesis that context effects in attitude measurement 'are greater in the case of weaker attitudes has clearly been disconfirmed' (Krosnick \& Abelson, 1992, p. 193; see also Krosnick \& Schuman, 1988). In contrast, construal models specify the conditions under which we are likely to obtain similar reports at different points in time, namely the conditions under which context effects will be small or absent. Several variables determine how likely this is to be the case. 
First, no change is expected when the context of the attitude judgment remains the same, thus rendering the same information temporarily accessible at $t 1$ and $t 2$. Second, change is also not expected when the judgment is solely based on chronically accessible information which comes to mind at both points in time, a situation that may arise when the context does not provide relevant information (e.g. Sia, Lord, Blessum, Ratcliff \& Lepper, 1997). Third, even under conditions where the mental representations formed at both times include a considerable amount of different information, these differences in representation will only result in different judgments when the information used at $\mathrm{t} 1$ and $\mathrm{t} 2$ has different evaluative implications. Simply replacing one piece of information with a different one of similar valence will not change the evaluative judgment (e.g. Sia et al., 1997).

Finally, attitude judgments will be similar at different points in time when the size of context effects is small. On the one hand, including a piece of accessible information in the representation of the attitude object results in assimilation effects, i.e. more positive (negative) judgments when positive (negative) information is included in the representation (for a review see Schwarz \& Bless, 1992). The size of these assimilation effects decreases as the amount and evaluative consistency of other information included in the representation of the target increases (e.g. Bless, Igou, Schwarz \& Wänke, in press). Hence, adding an additional piece of information at $\mathrm{t} 2$ to a representation of the object that is otherwise identical with the representation used at $\mathrm{t}$, will only result in change if the initial representation was (a) based on a small amount of information, was (b) evaluatively inconsistent (in which case the new piece of information may tip the balance), or (c) the new information is more extreme than the average implications of the old information. On the other hand, including positive (negative) information in the representation of the standard against which the attitude object is evaluated, results in contrast effects (Schwarz \& Bless, 1992). The size of these contrast effects is again a function of the amount and evaluative consistency of other information used in forming a standard, paralleling the discussion of the size of assimilation effects.

In short, the variables that determine the size of context effects are also the variables that determine the stability of attitude judgments over time. Hence, construal models (e.g. Lord \& Lepper, in press; Schwarz \& Bless, 1992) are compatible with the observation of change as well as stability in attitude reports and specify the conditions under which each one should be observed. Moreover, they provide a parsimonious conceptualization of the conditions of attitude-behavior consistency.

\section{Attitude-behavior Relationship}

Theoretically, an observed relationship between an individual's attitude and his or her behavior may reflect (a) that the behavior serves as input into an attitude judgment, as suggested by Bem's (1972) self-perception theory; (b) that the attitude guides the individual's behavioral decisions; or (c) that the attitude judgment and the behavioral decision are based on the same input information. Since Wicker's (1969) conclusion that attitudes and behavior are essentially unrelated, social psychologists have made considerable progress in understanding the conditions under which strong attitudebehavior relations may be expected (for a review see Eagly \& Chaiken, 1993). These conditions can be well conceptualized in the framework of attitude construal models. 
From the perspective of these models, attitude-behavior consistency is to be expected to the extent that individuals draw on similar input information in forming an attitude judgment and a behavioral decision.

First, high attitude-behavior consistency is to be expected when the temporary representation formed of the attitude object at the time of judgment matches the temporary representation formed at the time of behavior. For example, Ramsey, Lord, Wallace, and Pugh (1994) observed that participants' attitudes towards former substance abusers were a better predictor of their behavior towards an exemplar when the description of the exemplar matched rather than mismatched participants' representation of the group, as assessed two weeks earlier. Because many exemplars provide a provide a poor match with our general representation of the category to which they belong, it is difficult to predict behaviors towards exemplars from attitude judgments about the category, resulting in the usually observed low attitude-behavior relationship.

Second, suppose that the attitude judgment is based on respondents' mood at the time of judgment (Schwarz \& Clore, 1996). In this case, we may be hard put to detect any attitude-behavior consistency unless respondents happen to be in the same mood in the behavioral situation and the behavior is inconsequential, thus rendering one's apparent affective response sufficient for a decision. Moreover, any other difference in processing motivation at the time of judgment and behavior is similarly likely to decrease the attitude-behavior relationship (e.g. Blessum, Lord \& Sia, 1998), When asked in a consumer survey how much we like a Volvo, for example, we are likely to draw on fewer features of the attitude object than when pondering whether to actually buy a Volvo, thus increasing the likelihood of mismatches between the two representations. In a similar vein, Wilson and his colleagues (for a review see Wilson \& Hodges, 1992) observed that writing an essay that justifies one's attitude judgment can undermine the attitude-behavior relationship - in writing the essay, participants draw on many aspects they may not consider in the behavioral situation, thus reducing the match between the relevant representations.

Third, as Millar and Tesser (1992) noted, we engage in some behaviors for their instrumental value in reaching a goal and in other behaviors for the pleasures they provide. If so, attitude judgments should be a better predictor of instrumental behaviors when the judgment is based on a consideration of the behavior's instrumental implications rather than hedonic implications. But attitude judgments based on our hedonic assessments of the behavior should be an excellent predictor for consummatory behaviors, i.e. behaviors we engage in for enjoyment. An elegant series of studies confirmed this variant of the general matching hypothesis (see Millar \& Tesser, 1992).

Fourth, numerous studies have shown that attitude-behavior consistency is higher when the individual has direct behavioral experience with the attitude object (for a review see Fazio \& Zanna, 1981). For example, Regan and Fazio (1977) observed that participants' attitudes toward a set of puzzles were better predictors of how much time they spent on each puzzle in a subsequent free play period when their ratings were based on prior behavioral experience than when they were not. Presumably, the behavioral experience resulted in a temporary representation that provided a better match with participants' experiences during the free play period.

Fifth, attitude-behavior consistency is likely to be higher when individuals take the context in which the behavior is to be performed into account when they form an 
attitude judgment. In most cases, however, attitude judgments are assessed without mentally instantiating the context in which the attitude object may be encountered, resulting in low attitude-behavior consistency. Hence, attitudes assessed in a 'cold' state, e.g. attitudes towards condom use assessed in a research setting, are poor predictors of actual behavior in a 'hot' state, like an actual romantic encounter (for a review see Loewenstein \& Schkade, 1999). A similar argument can be made for the role of subjective norms and perceptions of personal control, variables that figure prominently in Fishbein and Ajzen's (1975) theory of reasoned action and Ajzen's (1985) theory of planned behavior. As Lord and Lepper (in press) noted, these variables are unlikely to enter the representation of the attitude object itself, but are prominent in the representation of the behavioral situation. Accordingly, taking these variables into account increases our ability to predict actual behavior over the predictive value of the attitude judgment alone.

Finally, the matching assumption also explains why some measurement procedures are more likely to identify attitude-behavior consistency than others. As Fishbein and Ajzen (1975) demonstrated, we are more likely to observe attitude-behavior consistency when we use multiple behavioral criteria rather than a single criterion. In terms of the preceding discussion, an aggregation across multiple behaviors or multiple situations increases the likelihood that some matches are included in the assessment. Moreover, attitude-behavior consistency increases the better the attitude question matches the behavioral criterion. For example, respondents' evaluation of 'donating money to the Democratic party' is a better predictor of this particular behavior than their general evaluation of the Democratic party per se. Such matches between the attitude question and the target behavior again increase the likelihood that both responses are based on similar representations.

\section{Conclusions}

In combination, the above examples highlight that a noticeable consistency between attitude judgments and behavior is likely to emerge when both responses are based on similar input information. If so, however, we may hesitate to conclude that some preexisting attitude plays a causal role in the behavioral decision. Instead, the observed relationship may be rather spurious, reflecting that the attitude judgment and the behavioral decision are based on similar representations of the attitude object (see Schwarz \& Bohner, in press, for a more detailed discussion).

At a more fundamental level, construal models question the general usefulness of the traditional attitude concept. An 'attitude' is a hypothetical construct whose use needs to be justified on the basis of its explanatory power. Yet, there is little that the attitude concept explains that cannot be conceptualized in terms of more general judgment processes. On the one hand, a judgment approach easily accounts for the phenomena that challenge the assumption that people hold enduring attitudes: it predicts the conditions under which context effects are, or are not, likely to emerge and specifies their direction and size (see Schwarz \& Bless, 1992; Schwarz, Groves \& Schuman, 1998; Tourangeau, 1999). Moreover, it allows us to conceptualize the influence of individual differences between respondents and of questionnaire variables within a single conceptual framework (e.g. Sudman et al., 1996). On the other hand, a judgment approach can also account for the phenomena that presumably support the 
traditional attitude concept: It predicts the conditions of attitude stability over time as well as the conditions that govern the emergence and strength of attitude-behavior relations (see Schwarz \& Bohner, in press). Of course, we can save a beloved concept by redefining attitudes as the memory representations on which judgmental processes operate (e.g. Lord \& Lepper, in press; Tourangeau, 1992), but little explanatory power is gained by this definitional move. Instead, it may be time to acknowledge that the psychology of attitudes is simply the psychology of evaluative judgment.

\section{EPILOGUE}

As I learned from responses to an earlier draft of this paper, the musings offered in the preceding pages may be more controversial than I had expected. Ironically, some readers interpreted my remarks about blind spots of the traditional informationprocessing paradigm as a call for its wholesale replacement, whereas others interpreted the section on attitudes construction as yet another indication of this paradigm's imperialistic appetite. While the latter impression may be realistic, the former is at least unintended. That humans are information processors is a truism that can hardly be called into question. Moreover, the adoption of the information processing paradigm has stimulated tremendous progress in social judgment research. But more than a quarter century after its adoption, at a time when the informationprocessing perspective has become the dominant theoretical framework of our field, it behooves us well to consider the risk of blind spots. If the reviewed research is any indication, our understanding of human judgment, and the explanatory power of an information-processing perspective, will only benefit from a closer consideration of the interplay of affect, motivation, and cognition, an exploration of the poorly understood interplay of explicit and implicit processes, and a serious acknowledgement of the pragmatic and socially, as well as culturally, contextualized nature of human cognition.

\section{ACKNOWLEDGEMENTS}

I thank Gerd Bohner, Daniel Kahneman, Richard Nisbett, Daphna Oyserman, Ian Skurnik, Fritz Strack, Abraham Tesser, Paul van Lange, Robert Wyer, and two anonymous reviewers for helpful comments on all or parts of an earlier draft. Their advice was greatly appreciated, although not always heeded.

\section{REFERENCES}

Ajzen I. 1985. From intentions to actions: A theory of planned behavior. In Action Control: From cognition to behavior, Kuhl J, Beckman J (eds); Springer-Verlag: New York; 11-39. Allport GW. 1954. The Nature of Prejudice. Addison-Wesley: MA. 
Ashby FG, Isen AM, Turken AU. 1999. A neuropsychological theory of positive affect and its influence on cognition. Psychological Review 106: 529-550.

Banaji MR, Lemm KM, Carpenter SJ. in press. The social unconscious. In Blackwell Handbook of Social Psychology, Vol 1: Intraindividual processes, Tesser A, Schwarz N (eds); Blackwell: Oxford.

Bargh JA. 1997. The automaticity of everyday life. In Advances in Social Cognition, Wyer RS (ed.); Erlbaum: Mahwah, NJ; 1-61.

Bargh JA, Chartrand TL. 1999. The unbearable automaticity of being. American Psychologist 54: $462-479$.

Bargh JA, Chen M, Burrows L. 1996. Automaticity of social behavior: Direct effects of trait construct and stereotype activation on action. Journal of Personality and Social Psychology 71: $230-244$.

Bargh JA, Gollwitzer PM. 1994. Environmental control of goal directed action: Automatic and strategic contingencies between situations and behavior. Nebraska Symposium on Motivation 41: 71-124.

Bargh A, Raymond P, Pryor J, Strack F. 1995. Attractiveness of the underling: An automatic power-sex association and its consequences for sexual harassment and aggression. Journal of Personality and Social Psychology 68: 768-781.

Bassili JN. in press. Cognitive indices of social information processing. In Blackwell Handbook of Social Psychology, Vol. 1: Intraindividual Processes, Tesser A, Schwarz N (eds); Blackwell: Oxford.

Bechera A, Damasio H, Tranel D, Damasio AR. 1997. Deciding advantageously before knowing the advantageous strategy. Science 275: 1293-1295.

Bem DJ. 1970. Beliefs, Attitudes, and Human Affairs. Brooks/Cole: Belmont, CA.

Bem DJ. 1972. Self-perception theory. In Advances in Experimental Social Psychology, Berkowitz L (ed.); Academic Press: New York; 1-62.

Blair IV. in press. Implicit stereotypes and prejudice. In Future Directions in Social Cognition, Moskowitz G (ed.); Erlbaum: Mahwah, NJ.

Bless H. in press. The consequences of mood on the processing of social information. In Blackwell Handbook of Social Psychology, Vol. 1: Intraindividual Processes, Tesser A, Schwarz N (eds); Blackwell: Oxford.

Bless H, Bohner G, Schwarz N, Strack F. 1990. Mood and persuasion: A cognitive response analysis. Personality and Social Psychology Bulletin 16: 331-345.

Bless H, Clore GL, Schwarz N, Golisano V, Rabe C, Wölk M. 1996b. Mood and the use of scripts: Does being in a happy mood really lead to mindlessness? Journal of Personality and Social Psychology 71: 665-679.

Bless H, Igou ER, Schwarz N, Wänke M. in press. Reducing context effects by adding context information: The direction and size of context effects in political judgment. Personality and Social Psychology Bulletin.

Bless H, Schwarz N. 1999. Sufficient and necessary conditions in dual process models: The case of mood and information processing. In Dual Process theories in Social Psychology, Chaiken S, Trope Y (eds); Guilford: New York; 423-440.

Bless H, Schwarz N, Kemmelmeier M. 1996a. Mood and stereotyping: The impact of moods on the use of general knowledge structures. European Review of Social Psychology 7: 63-93.

Bless H, Strack F, Schwarz N. 1993. The informative functions of research procedures: Bias and the logic of conversation. European Journal of Social Psychology 23: 149-165.

Blessum KA, Lord CG, Sia TL. 1998. Cognitive load and positive mood reduce typicality effects in attitude-behavior consistency. Personality and Social Psychology Bulletin 24: 496-504.

Bodenhausen GV. 1993. Emotions, arousal, and stereotype-based discrimination: A heuristic model of affect and stereotyping. In Affect, Cognition, and Stereotyping: Interactive processes in group perception, Mackie DM, Hamilton DL (eds); Academic Press: San Diego, CA; $13-35$.

Bodenhausen GV, Kramer GP, Süsser K. 1994. Happiness and stereotypic thinking in social judgment. Journal of Personality and Social Psychology 66: 621-632.

Bohner G, Moskowitz G, Chaiken S. 1995. The interplay of heuristic and systematic processing of social information. European Review of Social Psychology 6: 33-68. 
Bornstein RF, D'Agostino PR. 1994. The attribution and discounting of perceptual fluency: Preliminary tests of a perceptual fluency/attributional model of the mere exposure effect. Social Cognition 12: 103-128.

Bower GH. 1981. Mood and memory. American Psychologist 36: 129-148.

Bruner JS. 1957. On perceptual readiness. Psychological Review 64: 123-152.

Cacioppo JT, Berntson GG, Crites SL. 1996. Social neuroscience: Principles of psychophysiological arousal and response. In Social Psychology: Handbook of Basic Principles, Higgins ET, Kruglanski A (eds); Guilford: New York; 72-101.

Carver CS. Self-regulation. in press. Blackwell Handbook of Social Psychology, Vol 1: Intraindividual processes, Tesser N, Schwarz N (eds); Blackwell: Oxford.

Chaiken S, Trope Y (eds). 1999. Dual-process Models in Social Psychology. Guilford: New York.

Chen M, Bargh JA. 1999. Nonconscious approach and avoidance behavioral consequences of the automatic evaluation effect. Personality and Social Psychology Bulletin 25: 215-224.

Choi I, Nisbett RE, Norenzayan A. 1999. Causal attribution across cultures: Variation and universality. Psychological Bulletin 125: 47-63.

Choi I, Nisbett RE, Smith EE. 1997. Culture, categorization, and inductive reasoning. Cognition 65: 15-32.

Clark HH, Clark EV. 1977. Psychology and Language. Harcourt Brace, Jovanovich: New York.

Clore GL, Schwarz N, Conway M. 1994. Affective causes and consequences of social information processing. In Handbook of Social Cognition, 2nd edn, Vol 1, Wyer RS, Srull TK (eds); Erlbaum: Hillsdale, NJ; 323-418.

Converse PE. 1964. The nature of belief systems in the mass public. In Ideology and Discontent, Apter DE (ed.); Free Press: New York; 206-261.

Cousins SD. 1989. Culture and self-perception in Japan and the United States. Journal of Personality and Social Psychology 56: 124-131.

Damasio AR. 1994. Descarte's Error: Emotion, Reason and the Human Brain. Grosset/Putnam: New York.

Devine PG. 1989. Stereotypes and prejudice: Their automatic and controlled components. Journal of Personality and Social Psychology 56: 5-18.

Devine PG, Hamilton DL, Ostrom TM (eds). 1994. Social Cognition: Impact on social psychology. Academic Press: San Diego, CA.

Dijksterhuis A, van Knippenberg A. 1998. The relation between perception and behavior, or how to win a game of trivial pursuit. Journal of Personality and Social Psychology 74: 865-877.

Dodd DH, Bradshaw JM. 1980. Leading questions and memory: Pragmatic constraints. Journal of Verbal Learning and Verbal Behavior 19: 695-704.

Doosje B, Spears R, Koomen W. 1995. When bad isn't all bad: Strategic use of sample information in generalization and stereotyping. Journal of Personality and Social Psychology 69: 642-655.

Dovidio JF, Fazio RH. 1992. New technologies for the direct and indirect assessment of attitudes. In Questions about Questions, Tanur J (ed.); Russell-Sage: New York; 204-237.

Dunning D. in press. On the motives underlying social cognition. Blackwell Handbook of Social Psychology, Vol 1: Intraindividual Processes, Tesser A, Schwarz N (eds); Blackwell: Oxford.

Dunning D, Cohen LH. 1992. Egocentric definitions of traits and abilities in social judgment. Journal of Personality and Social Psychology 63: 341-355.

Dunning D, Leuenberger A, Sherman DA. 1995. A new look at motivated inferences: Are selfserving inferences of success a product of motivational forces? Journal of Personality and Social Psychology 69: 59-68.

Eagly AH, Chaiken S. 1993. The Psychology and Attitudes. Harcourt Brace Jovanovich: Fort Worth, TX.

Fazio RH. 1995. Attitudes as object-evaluation associations: Determinants, consequences, and correlates of attitude accessibility. In Attitude Strength, Petty RE, Krosnick JA (eds); Erlbaum: Mahwah, NJ; 247-282.

Fazio RH, Zanna MP. 1981. Direct experience and attitude-behavior consistency. Advances in Experimental Social Psychology 14: 161-202. 
Fiedler K. 1988. Emotional mood, cognitive style, and behavior regulation. In Affect, Cognition, and Social Behavior, Fiedler K, Forgas J (eds); Hogrefe International: Toronto; $100-119$.

Fischhoff B. 1991. Value elicitation: Is there anything there? American Psychologist 46: $835-847$.

Fishbein M, Ajzen I. 1975. Belief, Attitude, Intention, and Behavior: An introduction to theory and research. Addison-Wesley: Reading, MA.

Fiske AP, Kitayama S, Markus HR, Nisbett RE. 1998. The cultural matrix of social psychology. In Handbook of Social Psychology, 4th edn, Vol. 2, Gilbert DT, Fiske ST, Lindzey G (eds); Random House: New York.

Fiske ST. 1992. Thinking is for doing: Portraits of social cognition from daguerreotype to laserphoto. Journal of Personality and Social Psychology 63: 877-889.

Fiske ST, Depret E. 1996. Control, interdependence and power: Understanding social cognition in its social context. European Review of Social Psychology 7: 31-62.

Forgas JP. 1981. What is social about social cognition? In Social Cognition. Perspectives on everyday understanding, Forgas JP (ed.); Academic Press: New York; 1-26.

Forgas JP. 1995. Emotion in social judgements: Review and a new affect infusion model (AIM). Psychological Bulletin 117: 39-66.

Giner-Sorolla R, Garcia MT, Bargh JA. 1999. The automatic evaluation of pictures. Social Cognition 17: 76-96.

Glaser J, Banaji MR. 1999. When fair is foul and foul is fair: Reverse priming in automatic evaluation. Journal of Personality and Social Psychology 77: 669-687.

Gollwitzer PM. 1999. Implementation intentions: Strong effects of simple plans. American Psychologist 54: 493-503.

Gollwitzer PM, Bargh JA (eds). 1996. The Psychology of Action. Guilford: New York.

Gollwitzer PM, Moskowitz GB. 1996. Goal effects on cognition and action. In Social Psychology: Handbook of basic principles, Higgins ET, Kruglanski A (eds); Guilford: New York.

Greenwald AG, Banaji MR. 1995. Implicit social cognition: Attitudes, self-esteem, and stereotypes. Psychological Review 102: 4-27.

Grice HP. 1975. Logic and conversation. In Syntax and Semantics, 3: Speech Acts, Cole P, Morgan JL (eds); Academic Press: New York.

Griffin D, Gonzalez R, Varey C. in press. The heuristics and bias approach to judgment under uncertainty. In Blackwell Handbook of Social Psychology, Vol 1: Intraindividual Processes, Tesser A, Schwarz N (eds); Blackwell: Oxford.

Hamilton DL, Katz LB, Leirer VO. 1980. Organizational processes in impression formation. In Person Memory: The cognitive basis of social perception, Hastie R et al (eds); Erlbaum: Hillsdale, NJ; 121-153.

Han JJ, Leichtman MD, Wang Q. 1998. Autobiographical memory in Korean, Chinese, and American children. Developmental Psychology 34: 701-713.

Heider F. 1958. The Psychology and Interpersonal Relations. Wiley: New York.

Heine SJ, Lehman DA. 1999. Culture, self-discrepancies, and self-satisfaction. Personality and Social Psychology Review 25: 915-925.

Higgins ET. 1996. Knowledge activation: Accessibility, applicability, and salience. In Social Psychology: Handbook of basic principles, Higgins ET, Kruglanski A (eds); Guilford: New York; $133-168$.

Higgins ET. 1997. Beyond pleasure and pain. American Psychologist 52: 1280-1300.

Higgins ET, Rholes WS, Jones CR. 1976. Category accessibility and impression formation. Journal of Experimental Social Psychology 13: 141-154.

Hilton DJ. 1995. The social context of reasoning: Conversational inference and rational judgment. Psychological Bulletin 118: 248-271.

Hilton DJ, Karpinski A. 2000. Attitudes and the Implicit Associations Test. Working paper. Department of Psychology: University of Michigan.

Hilton DJ, Slugoski BR. in press. Conversational processes in reasoning and explanation. Blackwell Handbook of Social Psychology, Vol 1: Intraindividual Processes, Tesser A, Schwarz N (eds); Blackwell: Oxford. 
Hilton JL, Darley JM. 1991. The effects of interaction goals on person perception. Advances in Experimental Social Psychology 24: 235-67.

Isen AM. 1984. Toward understanding the role of affect in cognition. In Handbook of Social Cognition, 1st edn, Vol. 3, Wyer RS, Srull TK (eds); Erlbaum: Hillsdale, NJ.

Isen AM, Shalker TE, Clark MS, Karp L. 1978. Affect, accessibility of material in memory, and behavior: A cognitive loop? Journal of Personality and Social Psychology 36: 1-12.

Jacoby LL, Kelley CM. 1987. Unconscious influences of memory for a prior event. Personality and Social Psychology Bulletin 13: 314-36.

Jacoby LL, Kelley CM, Dywan J. 1989. Memory attributions. In Varieties of Memory and Consciousness: Essays in honour of Endel Tulving, Roediger HL, Craik FIM (eds); Erlbaum: Hillsdale, NJ; 391-422.

James W. 1890. The Principles of Psychology, Vol. 2. Henry Holt: New York.

Ji L, Schwarz N, Nisbett RE. in press. Culture, autobiographical memory, and behavioral frequency reports: Measurement issues in cross-cultural studies. Personality and Social Psychology Bulletin.

Kahneman D, Slovic P, Tversky A (eds). 1982. Judgment under Uncertainty: Heuristics and biases. Cambridge University Press: Cambridge.

Keltner D, Ellsworth PC, Edwards K. 1993. Beyond simple pessimism: Effects of sadness and anger on social perception. Journal of Personality and Social Psychology 64: 740-52.

Kirsch I, Lynn SJ. 1999. Automaticity in clinical psychology. American Psychologist 54: 504515.

Klayman J, Ha Y. 1987. Confirmation, disconfirmation, and information in hypothesis testing. Psychological Review 94: 211-228.

Krech D, Crutchfield RS. 1948. Theory and Problems of Social Psychology. McGraw-Hill: New York.

Krosnick JA, Abelson RP. 1992. The case for measuring attitude strength. In Questions about Questions, Tanur M (ed.); Russel-Sage: New York; 177-203.

Krosnick JA, Li F, Lehman DR. 1990. Conversational conventions, order of information acquisition, and the effect of base rates and individuating information on social judgment. Journal of Personality and Social Psychology 59: 1140-1152.

Krosnick JA, Schuman H. 1988. Attitude intensity, importance, and certainty and susceptibility to response effects. Journal of Personality and Social Psychology 54: 940-952.

Kruglanski A. 1996. Motivated social cognition: Principles of the interface. In Social Psychology: Handbook of basic principles, Higgins ET, Kruglanski A (eds); Guilford: New York; 493-520.

Kuhl J. 1983. Emotion, Kognition und Motivation, II [Emotion, cognition, and motivation, II]. Sprache und Kognition 4: 228-253.

Kuhn TS. 1962. The Structure of Scientific Revolutions. University of Chicago Press: Chicago, IL.

Kunda Z. 1990. The case for motivated reasoning. Psychological Bulletin 108: 331-350.

Kunda Z. 1999. Social Cognition: Making sense of people. MIT Press: Cambridge, MA.

Kunst-Wilson WR, Zajonc RB. 1980. Affective discrimination of stimuli that cannot be recognized. Science, 207: 557-558.

Lachman R, Lachman JT, Butterfield EC. 1979. Cognitive Psychology and Information Processing. Erlbaum: Hillsdale, NJ.

LeDoux J. 1996. The Emotional Brain. Simon \& Schuster: New York.

LeDoux J, Armony J. 1999. Can neurobiology tell us anything about emotional feelings? In Well-being: The foundations of hedonic psychology, Kahneman D, Diener E, Schwarz N (eds); Russell-Sage: New York; 489-499.

Lerner JS, Keltner D. in press. Beyond valance: Toward a model of emotion-specific influences on judgment and choice. Cognition \& Emotion.

Levine JM, Resnick LB, Higgins ET. 1993. Social foundations of cognition. Annual Review of Psychology 44: 585-612.

Lloyd GER. 1990. Demystifying Mentalities. Cambridge University Press: New York.

Loewenstein G, Schkade D. 1999. Wouldn't it be nice?: Predicting future feelings. In Wellbeing: The foundations of hedonic psychology, Kahneman D, Diener E, Schwarz N (eds); Russell-Sage: New York; 85-105. 
Loftus EF. 1979. Eyewitness Testimony. Harvard University Press: Cambridge, MA.

Lord CG, Lepper MR. in press. Attitude representation theory. In Advances in Experimental Social Psychology 31: 00-00.

Macrae CN, Bodenhausen GV, Milne AB, Jetten J. 1994. Out of mind but back in sight: Stereotypes on the round. Journal of Personality and Social Psychology 67: 808-817.

Markus HR, Kitayama S. 1991. Culture and self: Implications for cognition, emotion, and motivation. Psychological Review, 98: 224-253.

Martin LL, Clark LF. 1990. Social cognition: Exploring the mental processes involved in human social interaction. In Cognitive Psychology: An international review, Eysenck MW (ed.); Wiley: Chichester; 265-310.

Martin LL, Seta JJ, Crelia RA. 1990. Assimilation and contrast as a function of people's willingness to expend effort in forming an impression. Journal of Personality and Social Psychology 59: 27-37.

Martin LL, Strack F, Stapel D. in press How the mind moves: Knowledge accessibility and the fine-tuning of the cognitive system. In Blackwell Handbook of Social Psychology, Vol 1: Intraindividual Processes, Tesser A, Schwarz N (eds); Blackwell: Oxford.

Martin LL, Tesser A (eds). 1996. Striving and Feeling: Interactions among goals, affect, and selfregulation. Erlbaum: Mahwah, NJ.

Martin LL, Ward DW, Achée JW, Wyer RS. 1993. Mood as input: People have to interpret the motivational implications of their moods. Journal of Personality and Social Psychology 64: 317-326.

McCann CD, Higgins ET. 1992. Personal and contextual factors in communication: A review of the 'communication game'. In Language, Interaction, and Social Cognition, Semin GR, Fiedler K (eds); Sage: Newbury Park, CA; 144-172.

Millar MG, Tesser A. 1992. The role of beliefs and feelings in guiding behavior: The mismatch model. In The Construction of Social Judgments, Tesser A, Martin LL (eds); Erlbaum: Mahwah, NJ.

Miller AG, Schmidt D, Meyer C, Colella A. 1984. The perceived value of constrained behavior: Pressures toward biased inference in the attitude attribution paradigm. Social Psychology Quarterly 47: 160-171.

Miller DT, Ross M. 1975. Self-serving biases in attribution of causality: Fact or fiction? Psychological Bulletin 82: 213-225.

Miller JG. 1984. Culture and the development of everyday social explanation. Journal of Personality and Social Psychology 46: 961-978.

Miller JT. in press. The cultural grounding of social psychological theory. In Blackwell Handbook of Social Psychology, Vol 1: Intraindividual Processes, Tesser A, Schwarz N (eds); Blackwell: Oxford.

Morris MW, Peng K. 1994. Culture and cause: American and Chinese attributions for social and physical events. Journal of Personality and Social Psychology 67: 949-971.

Nakamura H. 1985. Ways of Thinking of Eastern Peoples. University of Hawaii Press: Honolulu.

Neisser U. 1967. Cognitive Psychology. Appleton-Century-Crofts: New York.

Nisbett RE, Peng K, Choi I, Norenzayan A. in press. Culture and systems of thought: Holistic vs. analytic cognition. Psychological Review.

Nisbett RE, Ross L. 1980. Human Inference: Strategies and shortcomings of social judgment. Prentice Hall: New York.

Norenzayan A. 1999. Rule-based and experience-based reasoning: The cognitive consequences of intellectual traditions. Unpublished doctoral dissertation, University of Michigan, Ann Arbor, USA.

Norenzayan A, Schwarz N. 1999. Telling what they want to know: Participants tailor causal attributions to researchers' interests European Journal of Social Psychology 29: 1011-1020.

Oettingen G, Gollwitzer PM. in press Goal setting and goal striving. In Blackwell Handbook of Social Psychology, Vol 1: Intraindividual Processes, Tesser A, Schwarz N (eds); Blackwell: Oxford.

Ortony A, Clore GL, Collins A. 1988. The Cognitive Structure of Emotions. Cambridge University Press: London. 
Payne JW, Bettman JR, Johnson EJ. 1992. Behavioral decision making: A constructive processing approach. Annual Review of Psychology 43: 87-131.

Payne JW, Bettman JR, Johnson EJ. 1993. The Adaptive Decision Maker. Cambridge University Press: Cambridge.

Peng K, Nisbett RE. 1997. Cross-cultural similarities and differences in the understanding of physical causality. In Proceedings of the Conference on Culture and Science, Shield M (ed.); Kentucky State University Press: Frankfort, KY.

Peng K, Nisbett RE. 1999. Culture, dialectics, and reasoning about contradiction. American Psychologist 54: 741-754.

Raghunathan R, Pham MT. 1999. All negative moods are not created equal: Motivational influences of anxiety and sadness on decision making. Organizational Behavior and Human Decision Performance 79: 56-77.

Ramsey SL, Lord CG, Wallace DS, Pugh MA. 1994. The role of subtypes in attitudes towards superordinate social categories. British Journal of Social Psychology, 33: 387-403.

Reber R, Winkielman P, Schwarz N. 1998. Effects of perceptual fluency on affective judgments. Psychological Science 9: 45-48.

Regan DT, Fazio RH. 1977. On the consistency between attitudes and behaviors: Look to the method of attitude formation. Journal of Experimental Social Psychology 13: 28-45.

Resnick LB, Levine JM, Teasly SD (eds). 1991. Perspectives on Socially Shared Cognition. American Psychological Association: Washington, DC.

Root-Bernstein RS. 1989. Discovering: Inventing and solving problems at the frontiers of scientific knowledge. Harvard University Press: Cambridge, MA.

Ross M, Fletcher GJO. 1985. Attribution and social perception. In The Handbook of Social Psychology, Lindzey G, Aronson E (eds); Random House: New York; 73-122.

Sanitioso R, Kunda Z, Fong GT. 1990. Motivated recruitment of autobiographical memories. Journal of Personality and Social Psychology 59: 229-241.

Schneider D. 1991. Social cognition. Annual Review of Psychology 42: 527-561.

Schwarz N. 1990. Feelings as information: Informational and motivational functions of affective states. In Handbook of Motivation and Cognition: Foundations of social behavior, Higgins ET, Sorrentino R (eds); Guilford: New York; 527-561.

Schwarz N. 1994. Judgment in a social context: Biases, shortcomings, and the logic of conversation. Advances in Experimental Social Psychology 26: 123-162.

Schwarz N. 1996. Cognition and Communication: Judgmental biases, research methods, and the logic of conversation. Erlbaum: Hillsdale, NJ.

Schwarz N. 1998. Accessible content and accessibility experiences: The interplay of declarative and experiential information in judgment. Personality and Social Psychology Review 2: $87-99$.

Schwarz N. 1999. Self-reports: How the questions shape the answers. American Psychologist 54: $93-105$.

Schwarz N, Bless H. 1992. Constructing reality and its alternatives: Assimilation and contrast effects in social judgment. In The Construction of Social Judgments, Martin LL, Tesser A (eds); Erlbaum: Hillsdale, NJ.

Schwarz N, Bless H, Bohner G. 1991a. Mood and persuasion: Affective states influence the processing of persuasive communications. Advances in Experimental Social Psychology 24: 161-199.

Schwarz N, Bohner G. in press. The construction of attitudes. In Blackwell Handbook of Social Psychology, Vol. 1: Intraindividual Processes, Tesser A, Schwarz N (eds); Blackwell: Oxford.

Schwarz N, Clore GL. 1983. Mood, misattribution, and judgments of well-being: Informative and directive functions of affective states. Journal of Personality and Social Psychology 45: $513-523$.

Schwarz N, Clore GL. 1996. Feelings and phenomenal experiences. In Social Psychology: Handbook of basic principles, Higgins ET, Kruglanski A (eds); Guilford: New York; 433-465.

Schwarz N, Groves R, Schuman H. 1998. Survey methods. In Handbook of Social Psychology, 4th edn, Vol 1, Gilbert D, Fiske S, Lindzey G (eds); McGraw-Hill: New York; 143-179.

Schwarz N, Strack F, Hilton DJ, Naderer G. 1991. Judgmental biases and the logic of conversation: The contextual relevance of irrelevant information. Social Cognition 9: 67-84. 
Schwarz N, Strack F, Mai HP. 1991c. Assimilation and contrast effects in part-whole question sequences: A conversational logic analysis. Public Opinion Quarterly 55: 3-23.

Sia TL, Lord CG, Blessum K, Ratcliff CD, Lepper MR. 1997. Is a rose always a rose? The role of social category exemplar-change in attitude stability and attitude-behavior consistency. Journal of Personality and Social Psychology 72: 501-514.

Sigall H, Page R. 1971. Current stereotypes: A little fadin, a little faking. Journal of Personality and Social Psychology 18: 247-255.

Sinclair RC. 1988. Mood, categorization breadth, and performance appraisal: the effects of order of information acquisition and affective state on halo, accuracy, information retrieval, and evaluations. Organizational Behavior and Human Decision Processes 42: 22-46.

Sinclair RC, Mark MM, Clore GL. 1994. Mood-related persuasion depends on misattributions. Social Cognition 12: 309-326.

Singer JA, Salovey P. 1988. Mood and memory: Evaluating the network theory of affect. Clinical Psychology Review 8: 211-251.

Sorrentino RM, Higgins ET. 1986. Motivation and cognition: Warming up to synergism. In Handbook of Motivation and Cognition: The foundations of social behavior, Sorrentino RM, Higgins ET (eds); Guilford: New York; 3-20.

Sperber D, Wilson D. 1986. Relevance: Communication and cognition. Harvard University Press: Cambridge, MA.

Stepper S, Strack F. 1993. Proprioceptive determinants of emotional and nonemotional feelings. Journal of Personality and Social Psychology 64: 211-220.

Stich SP. 1990. Fragmentation of Reason. MIT Press: Cambridge, MA.

Strack F. 1988. Social Cognition: Sozialpsychologie innerhalb des Paradigmas der Informationsverarbeitung. [Social cognition: Social psychology in the paradigm of information processing]. Psychologische Rundschau 39: 72-82.

Strack F. 1992. The different routes to social judgments: Experiential versus informational strategies. In The Construction of Social Judgments, Martin LL, Tesser A (eds); Erlbaum: Hillsdale, NJ; 249-276.

Strack F, Martin L. 1987. Thinking, judging, and communicating: A process account of context effects in attitude surveys. In Social Information Processing and Survey Methodology, Hippler HJ, Schwarz N, Sudman S (eds); Springer-Verlag: New York; 123-148.

Strack F, Martin LL, Stepper S. 1988. Inhibiting and facilitating conditions of the human smile: A non-obtrusive test of the facial feedback hypothesis. Journal of Personality and Social Psychology 53: 768-777.

Strack F, Schwarz N, Bless H, Kübler A, Wänke M. 1993. Awareness of the influence as a determinant of assimilation versus contrast. European Journal of Social Psychology 23: $53-62$.

Sudman S, Bradburn NM, Schwarz N. 1996. Thinking about Answers: The application of cognitive processes to survey methodology. Jossey-Bass: San Francisco, CA.

Taylor SE. 1998. The social being in social psychology. In Handbook of Social Psychology, 4th edn, Vol. 1, Gilbert DT, Fiske ST, Lindzey G (eds); Random House: New York; 58-95.

Tetlock PE. 1992. The impact of accountability on judgment and choice: Toward a social contingency model. Advances in Experimental Social Psychology 25: 331-376.

Tetlock PE, Boettger R. 1989. Accountability: A social magnifier of the dilusion effect. Journal of Personality and Social Psychology 57: 388-398.

Tetlock PE, Boettger R. 1996. The dilution effect: Judgmental bias, conversational convention, or a bit of both? European Journal of Social Psychology 26: 915-934.

Tetlock PE, Levi A. 1982. Attribution bias: On the inconclusiveness of the cognitionmotivation debate. Journal of Experimental Social Psychology 18: 68-88.

Tourangeau R. 1992. Attitudes as memory structures: belief sampling and context effects. In Context Effects in Social and Psychological Research, Schwarz N, Sudman S (eds); SpringerVerlag: New York; 35-47.

Tourangeau R. 1999. Context effects on answers to attitude questions. In Cognition and Survey Research, Sirken MG, Herrmann DJ, Schechter S, Schwarz N, Tanur JM and Tourangeau R (eds); Wiley: New York; 111-132. 
Wegener DT, Petty RE, Smith SM. 1995. Positive mood can increase or decrease message scrutiny: The hedonic contingency view of mood and message elaboration. Journal of Personality and Social Psychology 6: 5-15.

Wegner DM. 1992. You can't always think what you want: Problems in the suppression of unwanted thoughts. Advances in Experimental Social Psychology 25: 193-225.

Wegner DM, Bargh JA. 1998. Control and automaticity in social life. In The Handbook of Social Psychology, Vol. 1, Gilbert D, Fiske ST, Lindzey G (eds); McGraw-Hill: New York; 446-496.

Wegner DM, Pennebaker JW (eds). 1993. Handbook of Mental Control. Prentice Hall: Englewood Cliffs, NJ.

Wegner DM, Wenzlaff RM. 1996. Mental control. In Social Psychology: Handbook of basic principles, Higgins ET, Kruglanski AK (eds); Guilford: New York; 466-492.

Weimer WB, Palermo DS. 1973. Paradigms and normal science in psychology. Science Studies 3: $211-244$.

Wicker AW. 1969. Attitudes versus actions: The relationship of verbal and overt behavioral responses to attitude objects. Journal of Social Issues 25: 41-78.

Wilson TD, Dunn DS, Kraft D, Lisle DJ. 1989. Introspection, attitude change, and attitudebehavior consistency. Advances in Experimental Social Psychology 22: 287-338.

Wilson TD, Hodges SD. 1992. Attitudes as temporary constructions. In The Construction of Social Judgments, Martin LL, Tesser A (eds); Erlbaum: Hillsdale, NJ; 37-65.

Winkielman P, Berntson GG, Cacioppo JT. in press. The psychophysiological perspective on the social mind. In Blackwell Handbook of Social Psychology, Vol 1: Intraindividual Processes, Tesser A, Schwarz N (eds); Blackwell: Oxford.

Winkielman P, Zajonc RB, Schwarz N. 1997. Subliminal affective priming resists attributional interventions. Cognition \& Emotion 11: 433-465.

Wittenbrink B, Judd CM, Park B. 1997. Evidence for racial prejudice at the implicit level and its relationship with questionnaire measures. Journal of Personality and Social Psychology 72: $262-274$.

Wright EF, Wells GL. 1988. Is the attitude-attribution paradigm suitable for investigating the dispositional bias?. Personality and Social Psychology Bulletin 14: 183-190.

Wyer RS, Gruenfeld DH. 1995. Information processing in social contexts: Implications for social memory and judgment. Advances in Experimental Social Psychology 27: 49-91.

Wyer RS, Clore GL, Isbell LM. 1999. Affect and information processing. Advances in Experimental Social Psychology 31: 1-77.

Zajonc RB. 1968. Attitudinal effects of mere exposure. Journal of Personality and Social Psychology 9(Suppl. 2): 1-27.

Zajonc RB. 1980. Feeling and thinking. Preferences need no inferences. American Psychologist 35: $151-175$.

Zillman D. 1978. Attribution and misattribution of excitatory reactions. In New Directions in Attribution Research, Vol. 2, Harvey JH, Ickes WI, Kidd RF (eds); Erlbaum: Hillsdale, NJ; $335-368$. 